Int. J. Dev. Biol. 53: 91-99 (2009)

doi: $10.1387 / \mathrm{ijdb} .082677 \mathrm{sb}$

\title{
The heart forming region of early chick embryo is an alternative source of embryonic stem cells
}

\author{
SEEMA BORGAVE, KIRTI GHODKE and SURENDRA GHASKADBI* \\ Division of Animal Sciences, Agharkar Research Institute, Pune, INDIA
}

\begin{abstract}
In early chick embryo, the precardiac cells reside within distinct groups of mesodermal cells known as presumptive heart forming regions (HFRs). HFRs are located on the lateral sides of the Hensen's node. In an effort to study fate of HFRs in isolation, HFRs were excised from early gastrulating chick embryos and cultured in vitro. A very small proportion of HFRs from $18 \mathrm{~h}$ incubated embryos differentiated into beating cardiomyocytes whereas about $43 \%$ of HFRs from embryos incubated for longer durations $(20,23$ and $28 \mathrm{~h})$ showed beating activity. The potential of HFRs, from $18 \mathrm{~h}$ incubated embryos, to differentiate into cardiomyocytes increased significantly in presence of Hensen's node. About one third of the HFR cells underwent spontaneous differentiation into adipocytes in culture. Simultaneously, some of the cells derived from HFRs exhibited alkaline phosphatase (AP) activity indicating presence of stem cells in the culture. HFR cells were positive for vimentin indicating their mesenchymal origin. FGF supplement increased the proportion of AP-positive cells in a dose dependent manner. The present study demonstrates that HFRs can serve as a source of mesenchymal stem cells which can be gainfully employed for various purposes. The results also suggest that even though the in vitrocultured HFRs from $18 \mathrm{~h}$ incubated HH stage 4 chick embryo retain the potential to undergo cardiac differentiation, certain instructive signals from Hensen's node may reinforce the fate.
\end{abstract}

KEY WORDS: heart forming region, Hensen's node, embryonic stem cell, chick embryo

\section{Introduction}

During embryogenesis heart is the first organ to function and it is required to support development of the rapidly growing vertebrate embryo. In birds, cardiac specification is regulated through two distinct signaling centers; pregastrula hypoblast (Yatskievych etal., 1997) and the anterior lateral endoderm (OrtsLlorca, 1963; Schultheiss et al., 1995; Yatskievych et al., 1997). Hypoblast-derived activin induces the epiblast cells to take up cardiac lineage (Yatskievych et al., 1997). Specification of these precardiac cells commences while the cells are still within the streak (Yatskievych et al., 1997). Signals continue to specify the precardiac cells through late gastrulation as these cells migrate out of the streak and form bilateral precardiac regions (GonzalezSanchez and Bader, 1990; Montgomery et al., 1994; Gannon and Bader, 1995). Anterior lateral (precardiac) endoderm, the other cardiogenic signaling center, secretes signaling molecules like insulin, insulin-like growth factor II, activin, bone morphogenetic proteins (BMPs) and fibroblast growth factors (FGFs). BMPs play an inductive role in cardiogenesis (Antin et al., 1996; Zhu et al., 1996) while activin A and FGF2 are able to mimic the cardiogenic effect of the anterior lateral endoderm (Lopez-Sanchez et al., 2002). Activin and FGF have been implicated in vertebrate heart development in several studies (Ariizumi et. al., 1991; Fukui and Asashima, 1994; Khot and Ghaskadbi, 2001). In fact FGF receptor mediated signaling is shown to be critical for terminal differentiation of precardiac myocytes and for the early development of the heart (Sugi et al., 1995). However, it has been suggested that once the cardiac progenitor cells are determined, their further differentiation can take place in absence of signals from the anterior lateral endoderm (Gannon and Bader, 1995).

The Hensen's node, Organizer of the early chick embryo,

Abbreviations used in this paper: AP, alkaline phosphatase; bFGF, basic fibroblast growth factor; CEE, chick embryo extract; CS, chick serum; DMEM, Dulbecco's Modified Eagle Medium; FBS, fetal bovine serum; HFR, heart forming region; HH, Hamburger-Hamilton; MCA, 3'-methylcholanthrene; PBS, phosphate buffered saline.

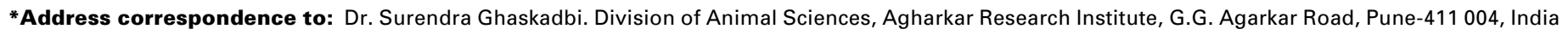
Fax: +91-20-2565-1542. e-mail: ghaskadbi@gmail.com
} 


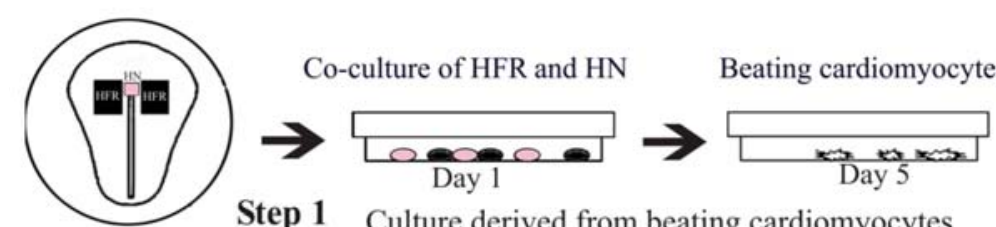

Step 1 Culture derived from beating cardiomyocytes
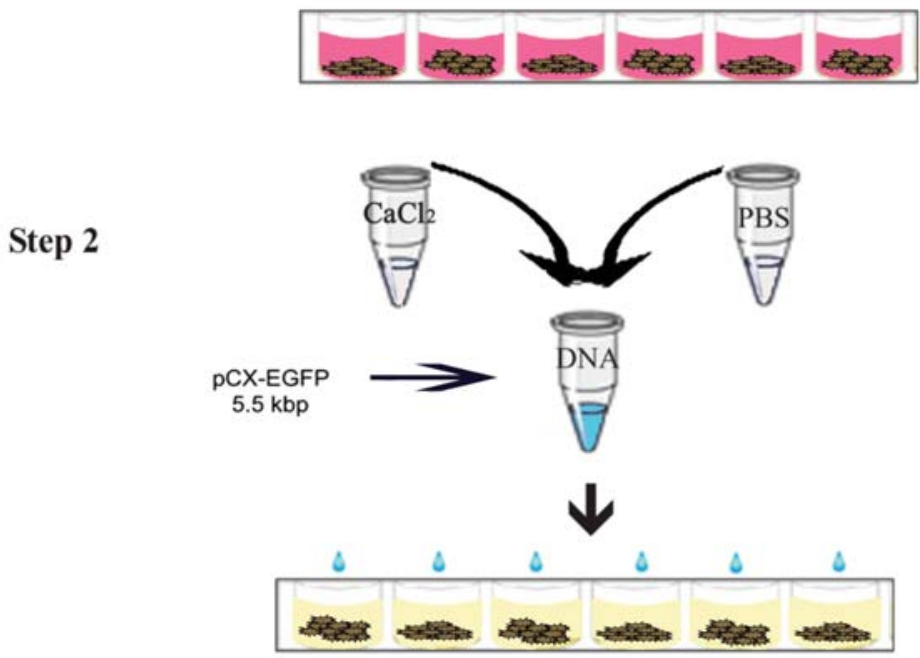

The medium was changed after $6 \mathrm{hrs}$ incubation.

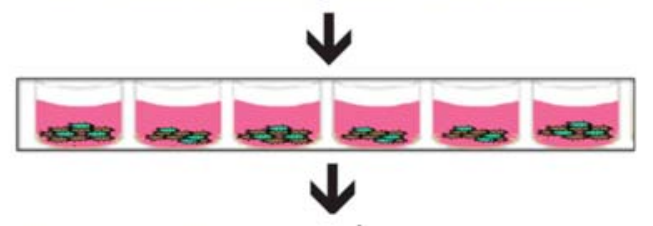

Transfected cells were injected in the subgerminal cavity.
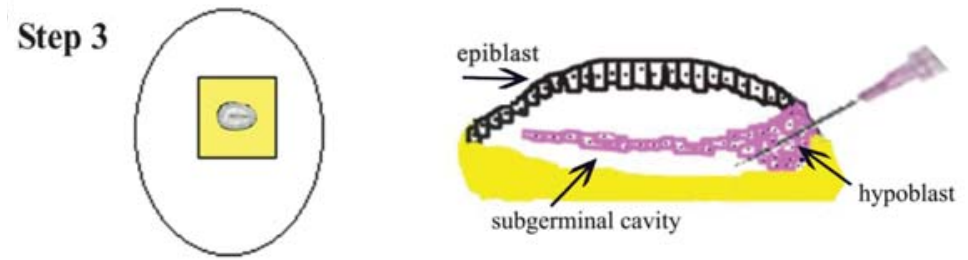

Egg with window made in the shell

Fig. 1. Experimental strategy. (Step1) Culture of HFR cells. Localization of precardiac cells at HH stage 4 based on the fate maps determined by GarciaMartinez and Schoenwolf, 1993 and Redkar et al., 2001. Precardiac cells reside on the bilateral sides of the Hensen's node in the regions shown in black. These regions are refereed to as presumptive heart forming regions (HFRs). Hensen's node $(H N)$ is shown in pink. Almost $50 \%$ of the HFRs, cultured along with HN, develop beating foci after 5 days in culture. These are selected and subcultured. (Step 2) Transfection of cells. pCX-EGFP containing the cDNA coding for enhanced green fluorescence protein is used for transfection of HFR cells. The cells are incubated in a mixture of $\mathrm{CaCl}_{2}, P B S$ and $\mathrm{pCX}$-EGFP DNA for $6 \mathrm{~h}$ after which the calcium-phosphate-DNA suspension is replaced with normal medium (refer to Materials and Methods for detailed protocol). About $30 \%$ of the cells are successfully transfected (shown in green). (Step 3) Injection of EGFP-transfected cells into the subgerminal cavity of gastrulating chick embryos. EGFP transfected cells are dissociated into single cell suspension. For in ovo injection of the cells, a piece of the eggshell is removed to make a window on the lateral side of the egg. A crosssectional view of the early chick blastoderm on the right shows two cell layers- the dorsal epiblast and ventral hypoblast. HFR cells are injected in the subgerminal cavity, the area between the newly migrating hypoblast and the yolk ball. secretes members of the FGF and TGF $\beta$ families during early heart development (Streit et al., 1998; Boettger et al., 1999). Grafting of Hensen's node or FGF-2- and FGF4-soaked beads induces cardiogenesis at ectopic sites in the host embryo (Lopez-Sanchez et al., 2002). In spite of all these studies the cellular and molecular mechanisms that underlie initiation of cardiogenesis and subsequent morphogenesis of the heart are still largely unclear (AbuIssa and Kirby, 2007). In the present study we have studied the auto-differentiation potential of precardiac cells which can be further explored to elucidate the molecular events during cardiogenesis.

It is quite difficult to isolate and maintain cardiac progenitor cells in culture since they are low in number, sensitive to manipulation and survive poorly in long-term culture (Eisenberg and Bader, 1996). In the present study we have cultured the presumptive heart forming region (HFR) comprising of both anterior lateral mesoderm and endoderm from early gastrulating chick embryos and monitored their growth under a variety of culture conditions. HFRs are believed to contain multipotent stem cells (Eisenberg et al., 2004). In the present study we have confirmed presence of stem cells in the presumptive HFRs. In varied environmental conditions these cells differentiated into different cell types suggesting their multipotent nature. Cultured HFR cells were amenable to transfection with foreign DNA and were able to incorporate themselves in the host embryo when injected in the subgerminal cavity (see Fig. 1). HFRs thus appear to be a good source of embryonic stem cells, which can be utilized as a tool to investigate embryonic development and differentiation.

\section{Results}

\section{Culture of HFRs with or without Hensen's nodes from 18 incubated chick embryos}

Both, tissue fragments from the co-culture of HFRs and Hensen's nodes and HFRs alone, could adhere to the plates within $24 \mathrm{~h}$. Following this, the cells began migrating out from the explants and formed distinct foci. About half of the HFRs co-cultured with Hensen's node exhibited regular, rhythmic beating activity by $5^{\text {th }}$ day in culture (Table 1). The beating continued till day 7 . If the beating foci were picked up by cell scraper and subcultured under identical conditions, the cells lost their beating activity.

Cells derived from the beating foci were treated with 3'methylcholanthrene (MCA), an immortalizing agent (Eisenberg and Bader, 1996). Another group of cells treated with DMSO served as a solvent control. By passage 3 , cells from the untreated group (master controls) showed heterogeneous morphologies; cells were cuboidal, polygonal or spindle-shaped (Fig. 2A). Majority of the DMSO- (Fig. 2B) and MCA-treated cells (Fig. 2C) had a fibroblast-like appearance. A large number of dense bodies, which morphologically appeared to be fat droplets, were visible in all the cultures but more prominently in the untreated cells (Fig. 2A).

Cells from all the three groups were fed regularly by 
TABLE 1

\section{CULTURE OF HFRS WITH OR WITHOUT HENSEN'S NODE FROM 18 H INCUBATED EMBRYOS}

\begin{tabular}{lcc} 
Tissue combinations & Number of pieces & Number of beating foci on day $\mathbf{5}$ \\
\hline HFR & 35 & $1(2.85 \%)$ \\
HFR + Hensen's node & $17+17$ & $8(47 \%)$ \\
HFR + posterior primitive streak & $5+5$ & None \\
HFR + notochord & $3+3$ & None \\
\hline
\end{tabular}

replacing the culture medium Dulbecco's Modified Eagle Medium (DMEM) with $20 \%$ fetal bovine serum (FBS), $2 \%$ chick serum (CS) and $2.5 \%$ chick embryo extract (CEE) every four days. Addition of CEE was found to be essential for the sustenance of cells in culture for initial passages. After a few passages, CEE was withdrawn from the culture medium since untreated, DMSO- and MCA-treated cells could grow well even in its absence. After the $3^{\text {rd }}$ passage cells from untreated and MCA-treated groups started attaining confluency much more rapidly, within 4 days. By passage 7 , the cells exhibited a different morphology suggesting that the cells had adapted to the culture conditions (Fig 2D-F). Individual cells appeared to pile up on each other in both untreated (Fig. 2D) and MCA-treated groups. In DMSO-treated group the cell population was sparse and the cells appeared fibroblast-like (Fig. 2E). Cells from MCA-treated group showed a peculiar arrangement. Small patches of cuboidal epithelial-like cells were surrounded by fibroblast-like cells (Fig 2F). In both untreated and MCA-treated groups the cells would start detaching from the plate soon after confluency.

Thus, cells derived from the beating foci were maintained in healthy condition for 120 days in culture and could be maintained up to passage 10 in both the master controls and MCA-treated groups. Most of the DMSO-treated cells appeared vacuolated and unhealthy. In contrast to HFR and Hensen's node co-cultures,

Fig. 2. In vitro culture and characterization of HFR cells from gastrulating chick embryo. (A-C) HFR cells at passage 3. Note cells with heterogeneous morphologies like cuboidal, polygonal or spindle shape in master-control group (A). In DMSO-treated (B) and MCAtreated (C) groups, fibroblast-like cells are abundant. (D-F) HFR cells at passage 7. The morphology of cells from untreated (D) and MCA-treated (F) groups is altered by passage 7. Note piling of cells on each other in these groups (arrowhead, D, F). Note sparse cell population in DMSOtreated group (E). A peculiar arrangement of cells from the MCA-treated group is evident (F). Cuboidal epithelial-like cells (arrow) are surrounded by spindle shaped fibroblast-like cells (asterisk). (G-I) AP activity in HFR cells at passage 3. Cells with blue represent cells that express AP. Very few cells from the untreated group exhibit AP-positive staining (G). DMSO-treated cells $\mathbf{( H )}$ show moderate presence of AP, while AP is maximally seen in the MCA-treated group (I). (J-L) AP activity in HFR cells at passage 7 . The untreated (J) and MCA-treated (L) cells exhibit a change in AP staining pattern, along with changes in morphology by passage 7. Note increased staining in untreated cells as compared to passage 3 (J). Cells from DMSO-treated group are negative for AP activity (K). In the MCA-treated group, only the central cuboidal cells (arrow) show staining, while the surrounding fibroblast-like cells (arrowhead) are negative for staining (L). (M-O) Oil-Red-O staining in cells at passage 3. Note the presence of reddish pink fat droplets in untreated (see arrow in (M)), DMSO-treated $(\mathbf{N})$ and MCA-treated (0) groups. Untreated cells show more number of cells with stained droplets as compared to DMSO-and MCAtreated cells. (P) Vimentin expression in HFR cells. Green fluorescence localizing vimentin is observed in almost all the cells derived from HFR. Scale bar, $0.2 \mathrm{~mm}$
HFRs cultured alone exhibited beating activity only in one out of thirty five cases (Table 1). When HFRs were dissociated with TPVG $(0.1 \%$ Trypsin, $0.05 \%$ Glucose and $0.02 \%$ EDTA), the cells failed to adhere and grow (data not shown).

\section{HFRs do not need any additional substratum to grow}

Fibronectin is an extracellular matrix protein that helps cells to adhere. No difference was found in the adherence of HFR explants to the fibronectin-coated plates as compared to uncoated culture plates (data not shown). The tissue pieces could adhere to the plate within $24 \mathrm{~h}$ irrespective of the substratum and grew equally well in uncoated plates.

\section{Alkaline phosphatase expression in cultured HFRs}

In our HFR cultures some of the cells were positive for alkaline phosphatase (AP) activity. In passage 3 maximum expression of AP was seen in MCA-treated cells, followed by DMSO-treated
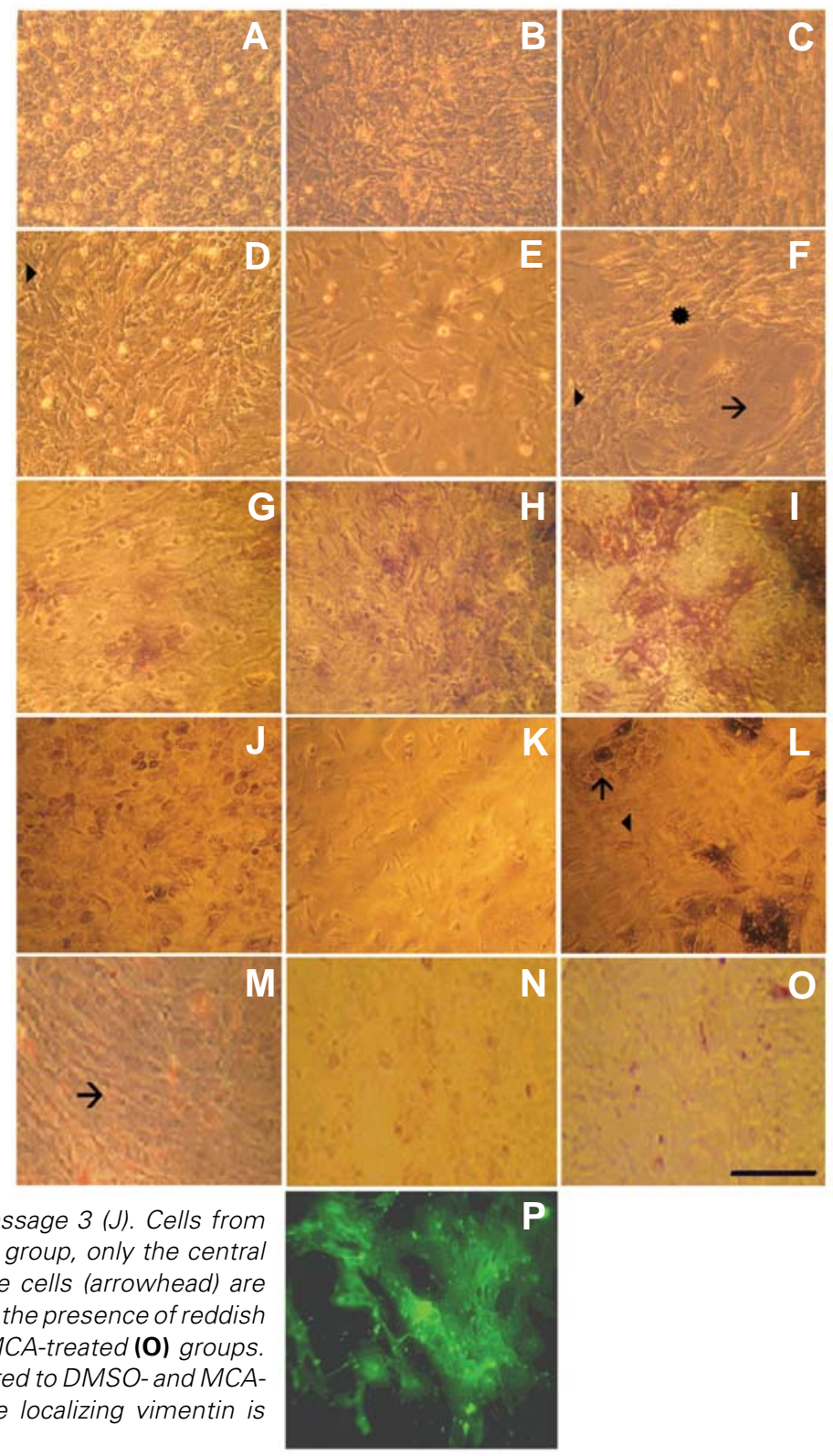
cells. Untreated cells showed very little staining for AP (Fig. 2GI).

Concurrent with the change in morphology, cells from untreated and MCA-treated groups exhibited change in AP activity profile by passage 7 . The proportion of stem cells appeared to have increased as indicated by increased staining in the untreated cells (Fig. 2J). DMSO-treated group had very few cells and these cells were negative for AP activity by passage 7 (Fig. 2K). In MCA-treated group only the central cuboidal cells were APpositive whereas AP activity was not detectable in the surrounding fibroblast-like cells (Fig. 2L).

\section{Presence of adipocytes}

Since some shiny intracellular bodies were observed by passage 3 , especially in the untreated cells, cells were stained with Oil-Red-O to check if these dense bodies were fat droplets that are typically seen in adipocytes. All three populations, untreated, DMSO- and MCA-treated, contained Oil-Red-O-positive cells. Number of cells with stained droplets was more in untreated group (Fig. 2M) in comparison with DMSO- (Fig. 2N) and MCA-treated (Fig. 2O) indicating that some of the mesenchymal cells might have spontaneously differentiated into adipocytes.

\section{Detection of vimentin}

Vimentin expression was studied only in the untreated cells (passage 3 ) as the DMSO- and MCA-treated cells were derived from the same group. Almost all of the cells were positive for vimentin (Fig. $2 \mathrm{P}$ ) indicating that the cultures derived from HFR indeed contained mesenchymal cells.

\section{Effects of basic fibroblast growth factor (bFGF)}

FGF treatment led to a significant increase in the number of AP-positive cells indicating more number of stem cells in the culture. AP activity was comparable in control (Fig. $3 \mathrm{~A}$ ) and $1 \mathrm{ng} /$ $\mathrm{ml} \mathrm{bFGF}$ treated groups (Fig. 3B) whereas $5 \mathrm{ng} \mathrm{bFGF/ml} \mathrm{led} \mathrm{to} \mathrm{a}$ significant increase in AP-positive cells (Fig. $3 \mathrm{C}$ ).

\section{Transfection of cells and their injection in recipient embryos}

When HFR cells transfected with plasmid $p C X$-EGFP, which harbors CDNA of enhanced green fluorescence protein, were observed under UV light 8 days after transfection, about $30 \%$ of the cells showed green fluorescence indicating successful transfection of these cells (Fig. 4A,B).

The embryos injected with EGFP transfected cells in the subgerminal cavity (Fig 1 ) were harvested on $5^{\text {th }}$ day postinjection. Prominent green fluorescence was detected along the

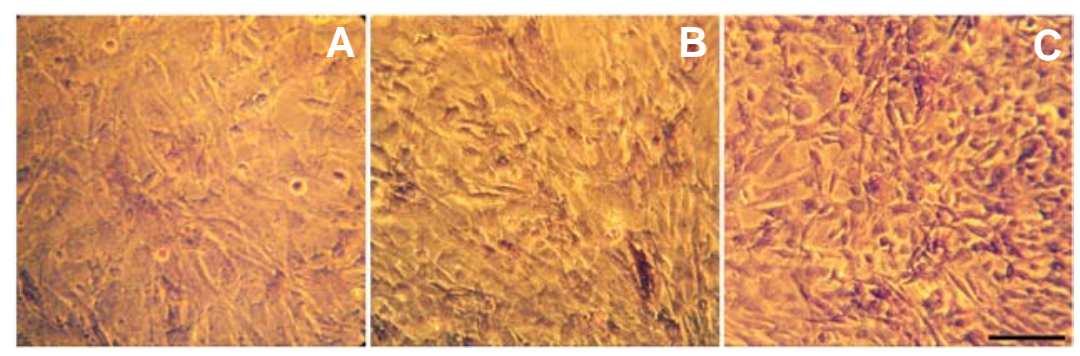

Fig. 3. Effect of bFGF treatment on AP activity. While AP activity is comparable in control (A) and $1 \mathrm{ng} / \mathrm{ml}$-bFGF treated group (B), the $5 \mathrm{ng} \mathrm{bFGF/m/} \mathrm{-treated} \mathrm{group}$ exhibits a significant increase in the number of AP positive cells (C). Scale bar, $0.1 \mathrm{~mm}$. developing blood vessels indicating that the injected cells could migrate and incorporate themselves into the host tissues (Fig. 4C,D). The HFR cells are thus found to be amenable to transfection with plasmid DNA. Further, the cells are capable of incorporating themselves in host tissue when injected in the subgerminal cavity.

\section{Grafting of HFR cells on early embryos}

HFR cells from $7^{\text {th }}$ passage were grafted at ectopic sites on $\mathrm{HH}$ stage 4 embryos cultured in vitro (Fig. 5A). At the end of $24 \mathrm{~h}$ of incubation, the grafts had adhered to the host tissue and appeared as dense tissue. By $40-41$ h post-grafting, about $80 \%$ of the hosts showed normal development of brain, heart and somites and had reached $\mathrm{HH}$ stage 14-15 of development.

Control embryos with whole Hensen's node grafts showed induction of secondary axis at the site of graft (Fig. 5B). The embryos grafted with cells of HFR had developed normally and about $80 \%$ (4/5 embryos) of such embryos showed blood formation in areas around the grafts (Fig. 5C).

\section{Discussion}

\section{Role of Hensen's node in avian cardiogenesis}

The present study demonstrates various fates of the anterior lateral mesoderm, which contains the precardiac mesoderm, excised along with the underlying endoderm from $18 \mathrm{~h}$ incubated, $\mathrm{HH}$ stage 4 chick embryo and cultured in vitro under different experimental conditions. We find that if HFRs are co-cultured with Hensen's node pieces from stage-matched embryo, the proportion of beating foci increases significantly from $2.8 \%$ to about $47 \%$. To confirm whether the required signals originate specifically from the Hensen's node, HFRs were cultured with pieces of either posterior primitive streak of stage 4 embryos or the newly emerged notochord from the next immediate staged ( $\mathrm{HH}$ stage 5$)$ embryos. The reason for selecting notochord pieces was that cells ingressing through the Hensen's node of stage 4 embryo mainly contribute to notochord, and continue to express some genes of Hensen's node like goosecoid (Izpisúa-Belmonte et al., 1993). Interestingly, only Hensen's node was found to provide the necessary signal(s) for the formation of rhythmically beating foci as the posterior primitive streak from stage 4 embryo as well as notochord from early stage 5 embryos, did not induce development of beating foci. The data clearly demonstrate that the Hensen's node is capable of providing the required signal(s) to the HFRs isolated from $18 \mathrm{~h}$ incubated HH stage 4 embryo.

Our results also suggest that in vitrocultured HFR cells from 18 $\mathrm{h}$ incubated $\mathrm{HH}$ stage 4 embryos retain a very limited potential to undergo cardiac differentiation on their own. At stage 4 the signals from the underlying anterior lateral endoderm, the second signaling center in cardiogenesis, thus may not be sufficient for the complete differentiation of cardiomyocytes in vivo. One of the ways to test this possibility is to examine if cardiac differentiation occurs in the absence of signals from the Hensen's node. It has been shown that HH stage $3^{+} / 4^{-}$chick embryos can develop normally with notochord, somites, head structures and heart even after complete ablation of the Hensen's node, but only under the conditions wherein the organizer is regener- 


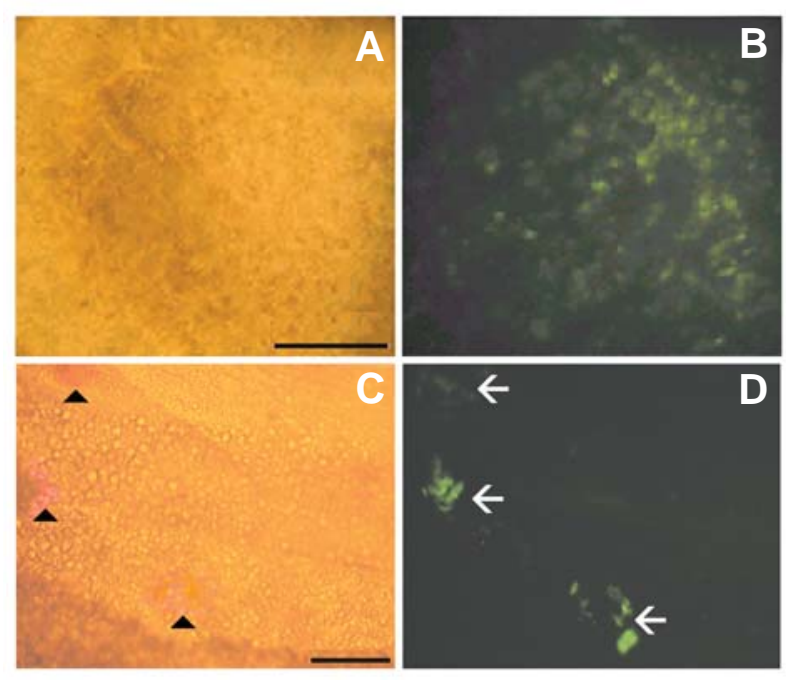

Fig. 4. Transfection of HFR cells and their incorporation into recipient embryos. Transfected cells observed under phase contrast (A) and under fluorescence (B) microscopy. Note green fluorescence in about $30 \%$ of the cells. (C,D) Embryos injected with EGFP-transfected cells in the subgerminal cavity. The embryo shows well developed blood patches (arrowheads) under phase contrast (C). The transfected cells become incorporated into the blood patches (arrows, D). Scale bars, $0.2 \mathrm{~mm}(A, B)$ and $(C, D)$.

ated (Psychoyos and Stern, 1996; Yuan and Schoenwolf, 1999). Development of a fully functional Hensen's node thus seems to be a prerequisite for the normal embryonic development. Hensen's node signals are thought to be important in the induction and patterning of the cardiovascular system too (Inagaki et al., 1993; Schoenwolf and Garcia-Martinez, 1995). Csal1, a member of Spalt family of transcriptional repressors, is expressed in the Hensen's node and primitive streak by $\mathrm{HH}$ stage 3 and appears to be important in cardiac morphogenesis (Sweetman et al., 2005). All these studies support our contention that besides early hypoblast and anterior lateral endoderm, Hensen's node may be one of the crucial signaling centers during cardiogenesis and plays an important role in cardiomyocytes differentiation. The cellular and molecular events occurring during the commitment and differentiation of precardiac cells are poorly understood. Our results suggest that the co-culture system of HFR and Hensen's node from stage 4 chick embryos may turn out to be a good model to study signaling pathways involved in cardiomyocyte differentiation.

Earlier studies have suggested that the HFRs from early chick ( $\mathrm{HH}$ stage 4 and onwards) and quail embryos (stage 4) can develop into beating cardiomyocytes within $48 \mathrm{~h}$ when cultured alone in vitro (DeHann, 1963; Montgomery et al., 1994; Gannon and Bader 1995; Eisenberg and Bader, 1996; Yatskievych et al., 1997; Eisenberg and Eisenberg, 1999). Our results do not agree with these reports since cardiac differentiation of HFR cells, in our hands, occurs only if the HFRs are co-cultured with the Hensen's node. This apparent discrepancy could be due to the following reasons. In the present study, we have always used $18 \mathrm{~h}$ incubated $\mathrm{HH}$ stage 4 chick embryo as mentioned frequently in the text. Studies from other laboratories use a wide incubation time window; 23-28 h for $\mathrm{HH}$ stage 4-6 chick embryos (Gannon and Bader, 1995), 20-48 h for HH stages 4-8 chick embryos (Mont- gomery etal., 1994), 20-30 h for stage 4-6 quail embryos (Eisenberg and Eisenberg, 1999) and 20-30 $\mathrm{h}$ incubated for quail stage 4 embryos (Eisenberg and Bader, 1996). Though none of the above reports mention the precise time of incubation to get a developmental stage, it is clear that at least $20 \mathrm{~h}$ incubated stage 4 chick/ quail embryos were used in these studies. The transition time between $\mathrm{HH}$ stages 4 and 5 in chick is quite long, almost 5 hours (Hamburger and Hamilton, 1951). It is indeed difficult to differentiate between the molecular make-up of embryos incubated for varying time periods within these $5 \mathrm{~h}$. We have scrupulously followed a combination of two criteria, $18 \mathrm{~h}$ incubation and morphological features, while selecting embryos during this study. In the earlier studies $20 \mathrm{~h}$ incubated embryos were used (Montgomery et al., 1994; Eisenberg and Bader, 1996; Gannon and Bader, 1995; Eisenberg and Eisenberg, 1999). It is therefore likely that the precise time at which HFRs are excised is crucial, especially since the HFRs are in close proximity of Hensen's node at these stages. To verify this possibility, we excised the HFRs from chick embryos incubated for various time intervals such as 20,23 and $28 \mathrm{~h}$ and cultured in vitrounder identical conditions that of $18 \mathrm{~h}$ incubated HFRs. $18 \mathrm{H}$ and $20 \mathrm{~h}$ incubated stage 4 embryos were morphologically indistinguishable from each other while 23 $\mathrm{h}$ incubated embryos were mostly of stage 5 and $28 \mathrm{~h}$ incubated embryos were at stage $6^{+} / 7$. In contrast to a small proportion of beating HFRs from $18 \mathrm{~h}$ incubated embryos (5 days post-culturing), more than $43 \%$ of HFRs from 20 and $23 \mathrm{~h}$ incubated embryos and about $73 \%$ of HFRs from $28 \mathrm{~h}$ incubated embryos showed rhythmic beating activity within $48 \mathrm{~h}$ (Table 2 ). Our results suggest that even though the $18 \mathrm{~h}$ and $20 \mathrm{~h}$ incubated stage 4 embryos look alike, they differ in their molecular make-ups and signals from the Hensen's node are essential for the HFRs of $18 \mathrm{~h}$ incubated $\mathrm{HH}$ stage 4 embryos to differentiate into beating cardiomyocytes.

We did not find any difference in the adherence of HFRs to the fibronectin-coated plates as compared to uncoated plastic surface of culture plates. However, it has been suggested that cardiomyocytes differentiation is facilitated if HFRs are spread on

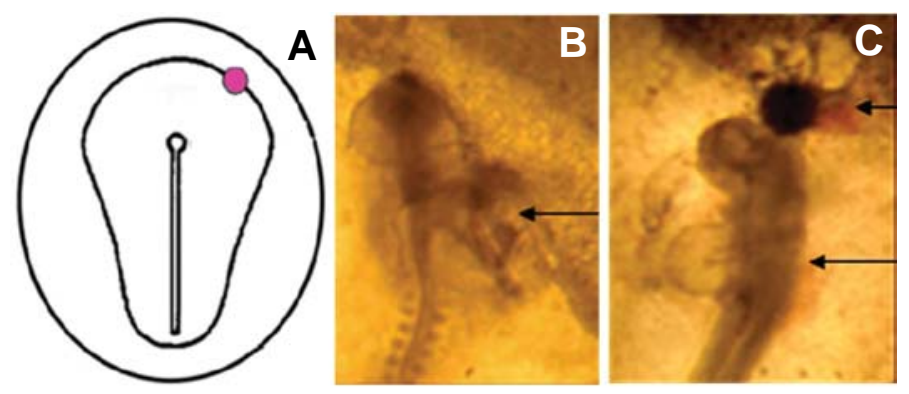

Fig. 5. Grafting of cells into cultured embryos. (A) Schematic representation of a stage 4 embryo wherein the graft position is indicated by magenta colour. (B) Note induction of secondary axis in the chick embryo with Hensen's node graft (arrow). The secondary axis has developed very close to the host axis and hampered the development of the host embryo. While grafting the HFR cell pellet on the host embryo, the graft was accidentally split into two unequal pieces. The major piece remained at 1 O'clock position, while the other piece moved and appeared to be incorporated into the host heart. (C) Note red areas indicating blood formation at both the sites where the graft pieces incorporated i.e. at 1 O'clock position and near heart (arrows, C). 
a semisolid medium (DeHann, 1963) and in most of the previous studies fibronectin coated plates were used to grow the isolated HFR pieces (Montgomery et al., 1994; Eisenberg and Bader, 1996; Gannon and Bader, 1995; Yatskievych et al., 1997; Eisenberg and Eisenberg, 1999). We did not find any advantage of using fibronectin coated plates over uncoated plastic plates.

In our hands, HFR cells perform better in culture if they are supplemented with chick embryonic extract for a few initial passages, an observation which is in agreement with Eisenberg and Bader (1996). It has been suggested that the HFR cells do not survive beyond 2 weeks in culture without immortalization (Eisenberg and Bader, 1996). In order to develop a long-term culture, we treated cells derived from beating HFR with an immortalizing agent, MCA (Eisenberg and Bader, 1996). We could, however, successfully maintain HFR cells with or without MCA treatment in culture for more than 120 days. The cells from both the groups appeared healthy throughout this period. We further found that HFR cells are amenable to transfection with a plasmid DNA that harbours EGFP cDNA and possessed the capacity to incorporate themselves in the host tissue when injected into the subgerminal cavity. Studies on characterization of these cells and the embryonic areas where they localize to are yet to be carried out. The ability of HFR cells to take up foreign DNA and integrate in host tissue makes it a powerful tool for molecular and cellular manipulation of early chick embryo and for following the fate of stem cells accurately.

\section{Presumptive heart forming region - a potential source of avian stem cells}

Precardiac mesoderm is known to contain multipotent stem cells (Eisenberg et al., 2004). AP is an enzyme expressed in stem cells ( $\mathrm{Li}$ et al., 2005). We therefore used AP activity as a marker to detect stem cells in HFR cultures. Some of the HFR cells from passage 3 were positive for AP activity. As expected MCA treatment led to expansion of stem cell population as indicated by significant increase in AP-positive cells. Untreated cells were rarely positive for AP at passage 3 suggesting the presence of fewer stem cells. Interestingly, by passage 7 , cells from untreated and MCA-treated groups exhibited change in AP profile concomitant with change in morphology. The proportion of stem cells appeared to have increased in untreated cells as compared to MCA-treated group.

Since FGF is essential for the maintenance and self-renewal of stem cells (Kelly et al., 2003), we studied its effect on HFR cells. Since stem cell maintenance is achieved by FGF only upto a certain concentration (Kelly et al., 2003), we used differing doses of basic FGF up to $5 \mathrm{ng} / \mathrm{ml}$. The proportion of AP positive cells increased with increasing dose of FGF indicating

TABLE 2

\section{DIFFERENTIATION CAPACITY OF HFRS ISOLATED FROM EARLY CHICK EMBRYOS}

\begin{tabular}{ccc} 
Incubation time (hrs) & Number of HFRs & Number of beating foci \\
\hline 18 & 35 & $1(2.85 \%)$ \\
20 & 39 & $17(43.58 \%)$ \\
23 & 52 & $23(44.23 \%)$ \\
28 & 42 & $31(73.8 \%)$ \\
\hline
\end{tabular}

the responsive nature of precardiac stem cells to FGF.

HFRs from $\mathrm{HH}$ stage 4 embryos could adhere very well to the culture plates without any matrix protein, a property of mesenchymal cells. The mesenchymal origin of the cells was therefore confirmed by presence of vimentin, an intermediate filament protein specifically expressed in mesenchymal cells (Yan et al., 2006). Almost all the cells were positive for vimentin confirming presence of mesenchymal cells in the HFRs of stage 4 embryos, an observation that is in agreement with Eisenberg et al. (2004).

Adipocyte is one of the derivatives of mesenchymal stem cells. Adipocytes secrete lipid droplets which can be detected with Oil-Red-O staining. Untreated HFR cells showed maximum number of cells with fat droplets indicating a large proportion of differentiated adipocytes in untreated as compared to MCA- and DMSO-treated cultures. MCA-treated cells showed the smallest proportion of adipocytes. These results suggest that some of the mesenchymal cells from HFR spontaneously differentiate into adipocytes while others remain as stem cells. These results correlate well with results with AP staining at passage 3 wherein MCA-treated cells show more stem cells and less differentiated cells.

Multipotent stem cells residing in HFR can generate a broad range of blood cell phenotypes if exposed to appropriate conditions (González-Sanchez and Bader, 1990; Eisenberg and Bader, 1996). Our results are in agreement with these observations. When cultured HFR cells were grafted at ectopic sites on whole chick embryos, the cells appeared to form blood at the sites of grafting. Further, when injected into the subgerminal cavity of the early chick embryos, the HFR cells were localized in the developing blood vessels of host embryos. Certain avian embryonic stem cells are capable of forming embryoid bodies if cultured in serum free conditions (Pain et al., 1996). In our study when the HFR cells were subjected to serum free conditions, the cells could form loose spherical aggregates which appeared somewhat like embryoid bodies but not as compact (data not shown).

The present results show that a proportion of HFR cells derived from $18 \mathrm{~h}$ incubated $\mathrm{HH}$ stage 4 embryos resemble stem cells in some of their features, such as, presence of AP activity, ability to differentiate into other cell types (adipocyte and blood cells) and formation of structures similar to embryoid bodies. These stem cells are of mesenchymal origin. Mesenchymal stem cells are multipotent cells that can differentiate into osteoblasts, chondrocytes, neurons, skeletal muscle cells, vascular endothelial cells and cardiomyocytes (Toma et al., 2002; Nagaya et al., 2005). To our knowledge, till date, avian embryonic stem cells have been derived only from very early stage X blastoderms (Eyal-Giladi and Kochav, 1976) and primordial germ cells (reviewed in Petitte et al., 2004). Present work shows for the first time that HFR of HH stage 4 embryo is a good source of avian embryonic mesenchymal stem cells.

Mouse embryonic stem cells are the most widely used model system to study growth and differentiation in vitro. However, harvesting stem cells from mouse embryos is quite laborious and technically challenging. In comparison, harvesting and maintaining embryonic stem cells from an early chick embryo is both technically less demanding and economical. Chick embryonic stem cells may therefore prove to be a useful alternative to 
mouse embryonic stem cells, at least in some studies. The possibility of using chick embryonic stem cells to generate transgenic birds with desired traits also exists.

\section{Materials and Methods}

\section{Preparation of chick embryo extract (CEE)}

Freshly laid White Leghorn chicken eggs were incubated for 18 hours at $37.5^{\circ} \mathrm{C}$ to obtain $\mathrm{HH}$ stage 4 embryos (Hamburger and Hamilton, 1951). Embryos were harvested by filter ring technique (Chapman et al., 2001). Embryo extract was prepared by homogenizing the whole blastoderm (area opaca and area pellucida) in DMEM (Invitrogen-Gibco, USA). One embryo was homogenated in $100 \mu \mathrm{IDMEM}$ and filtered through a $0.22 \mu \mathrm{m}$ filter. This stock was considered as $100 \%$.

\section{Tissue culture media}

The culture media used for HFR cells contained DMEM with low glucose (with L-glutamine, $100 \mathrm{mg} / \mathrm{l}$ sodium pyruvate, pyridoxine hydrochloride), $20 \% \mathrm{FBS}, 2 \% \mathrm{CS}, 100 \mathrm{U} / \mathrm{ml}$ penicillin and $100 \mu \mathrm{g} / \mathrm{ml}$ streptomycin. DMEM, FBS, CS and streptomycin were from Invitrogen-Gibco (USA) while penicillin was from Sigma (USA). For initial few passages, $2.5 \%$ CEE was added to the medium.

\section{Excision and in vitro culture of HFRs together with Hensen's nodes}

The cells destined to form cardiac tissue reside on the bilateral regions of the Hensen's node of a stage 4 embryo (Fig 1). The region containing these cells is referred to as heart forming region (HFR). $\mathrm{HH}$ stage 4 (18-h incubated) embryos were dissected out by filter ring technique (Chapman et al., 2001), the HFRs (anterior lateral mesoderm and underlying endoderm of approximately $1 \times 1 \mathrm{~mm}$ pieces) and the Hensen's nodes were excised and co-cultured in equal numbers. The cultures were maintained at $37^{\circ} \mathrm{C}$ and $5 \% \mathrm{CO}_{2}$. By fifth day in culture, one of the beating tissue fragments was scraped, seeded onto another plate and passaged when they became confluent. For initial four passages the cultures were maintained in the medium supplemented with $2.5 \%$ CEE. After 30 days in culture, a small population of these cells was treated with the immortalizing agent, MCA $(1 \mu \mathrm{g} / \mathrm{ml})$ for 6 days with a change of medium after 3 days (Eisenberg and Bader, 1996). Solvent controls (cells treated with $1 \mu \mathrm{l} / \mathrm{ml}$ DMSO) were maintained in an identical manner. After 6 days of treatment with either DMSO or MCA, the cells were transferred back to regular culture medium i.e., DMEM with $20 \%$ FBS and $2 \%$ CS. We thus had three populations of cells derived from beating HFRs; cells without any treatment (master controls) and cells treated either with DMSO or MCA. The cells were grown on coverslips and fixed at different passages for characterization. The HFR and Hensen's node co-culture experiments were replicated nine times to confirm the results. MCA, however, was used only in three of the nine experiments.

\section{Excision and in vitro culture of the HFRs from early chick embryos}

In these experiments, only HFRs from chick embryos incubated for different time intervals (18, 20, 23 and $28 \mathrm{~h}$ ) were excised and cultured under identical conditions as described earlier.

\section{Cell culture substratum}

To check if HFRs adhere better to coated surfaces, the tissue pieces were placed on the tissue culture plates (Tarsons, India) with or without fibronectin $\left(2 \mu \mathrm{g} / \mathrm{cm}^{2}\right.$, INC Biomedicals, USA) coating.

\section{Alkaline phosphatase reaction}

Cells grown on coverslips were fixed overnight in $4 \%$ paraformaldehyde at $4^{\circ} \mathrm{C}$. After several washes with PBS, cells were equilibrated in a solution containing $100 \mathrm{mM}$ Tris- $\mathrm{HCl}(\mathrm{pH} 9.5), 100 \mathrm{mM}$ sodium chloride, $50 \mathrm{mM}$ magnesium chloride and incubated in dark at $37^{\circ} \mathrm{C}$ with substrates (NBT-BCIP, Roche Molecular Biochemicals, Germany) for AP. The color reaction was terminated by replacing the color development solution with
1XPBS (pH 7.4). The coverslips were mounted in $50 \%$ glycerol in PBS, observed under inverted microscope (Leica, Germany) and photographed.

\section{Oil-Red-O staining for adipocytes}

The cells were fixed in $4 \%$ paraformaldehyde (overnight, $4^{\circ} \mathrm{C}$ ), washed with PBS and incubated at $37^{\circ} \mathrm{C}$ for $45-60$ min with Oil-Red-O stain (Sigma, USA). Cells were washed with PBS and observed as described before.

\section{Detection of vimentin}

Vimentin expression in the cells was studied by using indirect immunofluorescence as per Willingham (1999) with a few modifications. Unless stated otherwise all the steps were carried out at room temperature. Cells grown on coverslips were rinsed with PBS and fixed overnight in $4 \%$ paraformaldehyde at $4^{\circ} \mathrm{C}$. After a couple of PBS washes, the cells were subjected to a blocking solution containing $1 \%$ FBS and $0.1 \%$ saponin in PBS (Sigma, USA) for $10 \mathrm{~min}$. Antibody against vimentin raised in goat and FITC conjugated anti-goat IgG were used as primary and secondary antibodies, respectively. Both the antibodies were procured from Sigma, USA. The cells were incubated in anti-vimentin antibody (1:20) diluted in the blocking solution for $30 \mathrm{~min}$, washed with PBS and then incubated in 1:32 diluted secondary antibody for $30 \mathrm{~min}$. After a wash of PBS the cells were refixed in $4 \%$ paraformaldehyde, mounted in $50 \%$ glycerol and photographed under UV light.

\section{Treatment of cells with bFGF}

Cells were treated with two different concentrations of basic FGF ( 1 and $5 \mathrm{ng} / \mathrm{ml}$, Sigma, USA) for 6 days with a change on $3^{\text {rd }}$ day. The cells were fixed in $4 \%$ paraformaldehyde and processed for detection of AP activity.

\section{Transfection of cells and injection of EGFP-transfected cells into recipient embryos}

HFR cells were transfected with plasmid $p C X$-EGFP that harbors cDNA of enhanced green fluorescence protein under the ubiquitous promoter of chick $\beta$-actin. Calcium phosphate-mediated transfection (Sambrook and Russell, 2001) and injection of transfected cells in the subgerminal cavity of chick embryo was carried out as depicted in Fig. 1. In brief, culture with cells grown to $70 \%$ confluency was selected and medium was changed $1 \mathrm{hr}$ before transfection. Approximately $25 \mu \mathrm{g}$ plasmid DNA was mixed with $100 \mu \mathrm{l}$ of $2.5 \mathrm{M}$ calcium chloride. To this equal volume of $2 X$ PBS was added and mixed thoroughly at room temperature for $1 \mathrm{~min}$. Immediately the calcium phosphate-DNA suspension was added onto the cultures $(100 \mu$ l of DNA suspension $/ \mathrm{ml}$ medium) and the culture plate was rocked gently till the medium became yelloworange and turbid. The cells were incubated with the calcium phosphateDNA suspension at $37^{\circ} \mathrm{C}$ with $5 \% \mathrm{CO}_{2}$ for $6 \mathrm{~h}$, the medium was changed with fresh pre-warmed culture medium and incubation was continued at $37^{\circ} \mathrm{C}$ and $5 \% \mathrm{CO}_{2}$. After reaching confluency, the cells were trypsinised, replated and some of the cells were grown on coverslips to observe under UV light to check for transfection (expression of EGFP).

Transfected cells were trypsinised, suspended in DMEM supplemented with $20 \% \mathrm{FBS}$ and $2 \% \mathrm{CS}$ and injected in the subgerminal cavity of recipient embryos following the procedure of Pain et al., 1996, as shown in Fig. 1. HH stage 4 embryos were used as recipients. Small holes were made gently with a tungsten needle at the broader end (in the airspace of the egg). A small window was made on the lateral side of the egg and the shell along with the adhering shell membrane was removed. Some of the thin albumin was removed through the window and then the yolk ball was rotated gently so as to bring the embryo below the window. About 10 to $15 \mu$ l of cell suspension was injected in the subgerminal cavity of the embryo using an insulin syringe. The window was sealed with Durapore ${ }^{\circledR}$ tape and the eggs were incubated further. On $5^{\text {th }}$ day postinjection, embryo was taken out by cutting the vitelline membrane, cleaned with PBS and mounted on slides in $50 \%$ glycerol. The embryos 
were observed under UV light to check if the injected EGFP-positive cells became incorporated in the host embryo.

\section{Grafting of cells on in vitro cultured early embryos}

$\mathrm{HH}$ stage 4 embryos were cultured in vitrousing single ring technique (New, 1955) with modifications as described before (Khot and Ghaskadbi, 2001; Karandikar and Ghaskadbi, 2003; Patwardhan et al., 2004). To study the fate of cells derived from HFRs, the cells were grafted on the cultured embryos. Cells $\left(1.2 \times 10^{5} / \mathrm{ml}\right.$, passage 7$)$ were trypsined, aliquoted and centrifuged to get cell pellets of suitable size ( 12000 cells/pellet). The pellets were washed twice with Pannet Compton saline (New, 1966). Endoderm of the host embryo was scraped off at the site of grafting (1 O'clock position at the boundary of area pellucida and area opaca, Fig $5 \mathrm{~A})$. The pellets were transferred on to the host embryo and the development was monitored for $40-41 \mathrm{~h}$.

\section{Acknowledgement}

We thank Drs Ramesh Bhonde, Saroj Ghaskadbi, Anandwardhan Hardikar and Vidya Patwardhan for discussions and help. This work was supported through intramural funds from Agharkar Research Institute, Pune, India.

\section{References}

ABU-ISSA, R. AND KIRBY, M.L. (2007). Heart Field: From Mesoderm to Heart Tube. Annu. Rev. Cell Dev. Biol. 23: 45-68.

ANTIN, P.B., YATSKIEVYCH, T., DOMINGUEZ, J.L., CHIEFFI, P. (1996). Regulation of avian precardiac mesoderm development by insulin and insulin-like growth factor. J. Cell. Physiol. 168: 42-50.

ARIIZUMI, T., SAWAMURA, K., UCHIYAMA, H., ASASHIMA, M. (1991) Dose and time-dependent mesoderm induction and outgrowth formation by activin $A$ in Xenopus laevis. Int. J. Dev. Biol. 35: 407-414.

BOETTGER, T., WITTLER, L., KESSEL, M. (1999). FGF8 functions in the specification of the right body side of the chick. Curr. Biol. 9: 277-280.

CHAPMAN, S.C., COLLIGNON, J., SCHOENWOLF, G.C., LUMSDEN, A. (2001). Improved method for chick whole-embryo culture using a filter paper carrier. Dev. Dyn. 220: 284-289.

DEHANN, R.L. (1963). Migration patterns of the precardiac mesoderm in the early chick embryo. Exp. Cell Res. 29: 544-560.

EISENBERG, C.A., BADER, D. (1996). The establishment of the mesodermal cell line QCE-6: a model system for cardiac cell differentiation. Circ. Res. 78: 205216.

EISENBERG, C.A., EISENBERG, L.M. (1999). WNT11 promotes cardiac tissue formation of early mesoderm. Dev. Dyn. 216: 45-58.

EISENBERG, L.M., KUBALAK, S.W., EISENBERG, C.A. (2004). Stem cells and the formation of the myocardium in the vertebrate embryo. Anat. Rec. A Discov. Mol. Cell. Evol. Biol. 276: 2-12.

EYAL-GILADI, H., KOCHAV, S. (1976). From cleavage to primitive streak formation: a complementary normal table and a new look at first stages of the development of the chick. I General morphology. Dev. Biol. 49: 321-337.

FUKUI, A., ASAHSIMA, M. (1994). Control of cell differentiation and morphogenesis in amphibian development. Int. J. Dev. Biol. 38: 257-266.

GANNON, M., BADER, D. (1995). Initiation of cardiac differentiation occurs in the absence of anterior endoderm. Development 121: 2439-2450.

GARCIA-MARTINEZ, V., SCHOENWOLF, G.C. (1993). Primitive streak origin of the cardiovascular system in avian embryos. Dev. Biol. 159: 706-719.

GONZALEZ-SANCHEZ, A., BADER, D. (1990). In vitro analysis of cardiac progenitor cell differentiation. Dev. Biol. 139: 197-209.

HAMBURGER, V., HAMILTON, H.L. (1951). A series of normal stages in the development of the chick. J. Morphol. 88: 49-92.

INAGAKI, T., GARCIA-MARTINEZ, V., SCHOENWOLF, G.C. (1993). Regulative ability of the prospective cardiogenic and vasculogenic areas of the primitive streak during avian gastrulation. Dev. Dyn. 197: 57-68.

IZPISÚA-BELMONTE, J.C., DE ROBERTIS, E.M., STOREY, K.G., STERN, C.D.
(1993). The homeobox gene goosecoid and the origin of the organizer cells in the early chick blastoderm. Cel/74: 645-659.

KARANDIKAR, A., GHASKADBI, S. (2003). b-Microseminoprotein-related molecules may participate in formation of the mesoderm in the chick embryo. Dev. Growth Diff. 45: 309-319.

KELLY, C.M., ZIETLOW, R., DUNNETT, S.B., ROSSER, A.E. (2003). The effects of various concentrations of FGF-2 on the proliferation and neuronal yield of murine embryonic neural precursor cells in vitro. Cell Transplant. 12: 215-223.

KHOT, S., GHASKADBI, S. (2001). FGF signaling is essential for the early events in the development of the chick nervous system and mesoderm. Int. J. Dev. Biol. 45: 877-885.

LI, J., PAN, Q., LI., J., HAN, H., SUN, S., YANG, J., XU, S., TIAN, L., LIAN, Z., YANG, N., LI, N. (2005). Research of blastocyte-like structure in chicken. SCi. China Ser. C. Life Sci. 48: 481-486.

LOPEZ-SANCHEZ, C., CLIMENT, V., SCHOENWOLF, G.C., ALVAREZ, I.S., GARCIA-MARTINEZ, V. (2002). Induction of cardiogenesis by Hensen's node and fibroblast growth factors. Cell Tissue Res. 309: 237-249.

MONTGOMERY, M.O., LITVIN J., GONZALEZ-SANCHEZ, A., BADER, D. (1994). Staging of commitment and differentiation of avian cardiac myocytes. Dev. Biol. 164: 63-71.

NAGAYA, N., KANGAWA, K., ITOH, T., IWASE, T., MURAKAMI, S., MIYAHARA, Y., FUJII, T., UEMATSU, M., OHGUSHI, H.,ÄYAMAGISHI, M., TOKUDOME, T., MORI, H., MIYATAKE, K., KITAMURA, S. (2005). Transplantation of mesenchymal stem cells improves cardiac function in a rat model of dilated cardiomyopathy. Circulation 112: 1128-1135.

NEW, D. A. T. (1955). A new technique for the cultivation of chick embryo in vitro. J. Embryol. Exp. Morphol. 3: 326-331.

NEW, D.A.T. (1966). The Culture of Vertebrate Embryos. Logos Press, London, pp. 47-84.

ORTS-LLORCA, F. (1963). Influence of the endoderm on heart differentiation during the early stages of development of the chick embryo. Roux Arch. Dev. Biol. 154: 533-551.

PAIN, B., CLARK, M.E., SHEN, M., NAKAZAWA, H., SAKURAI, M., SAMARUT, J., ETCHES, R.J. (1996). Long-term in vitro culture and characterization of avian embryonic stem cells with multiple morphogenetic potentials. Development 122: 2339-2348.

PATWARDHAN, V., GOKHALE, M., GHASKADBI, S. (2004). Acceleration of early chick embryo morphogenesis by insulin is associated with altered expression of embryonic genes. Int. J. Dev. Biol. 48: 319-326.

PETITTE, J.N., LIU, G., YANG, Z. (2004). Avian pluripotent stem cells. Mech. Dev. 121: $1159-1168$.

PSYCHOYOS, D., STERN, C.D. (1996). Restoration of the organizer after radical ablation of Hensen's node and the anterior primitive streak in the chick embryo. Development 122: 3263-3273.

REDKAR, A., MONTGOMERY, M., LITVIN, J. (2001). Fate map of early avian cardiac progenitor cells. Development 128: 2269-2279.

SAMBROOK, J. AND RUSSELL, D.W. (2001). Molecular Cloning- $A$ Laboratory Manual, Vol. 3, Cold Spring Harbor Laboratory Press, New York.

SCHOENWOLF, G.C. and GARCIA-MARTINEZ, V. (1995). Primitive streak origin and state of commitment of cells of the cardiovascular system in avian and mammalian embryos. Cell. Mol. Biol. Res. 41: 233-240.

SCHULTHEISS, T.M., XYDAS, S., LASSAR, A.B. (1995). Induction of avian cardiac myogenesis by anterior endoderm. Development 121: 4203-4214.

STREIT, A., LEE, K.J., WOO, I., ROBERTS, K., JESSELL, T.M., STERN, C.D. (1998). Chordin regulates primitive streak development and the stability of induced neural cells, but is not sufficient for neural induction in the chick embryo. Development 125: 507-519.

SUGI, Y., SASSE, J., BARRON, M., LOUGH, J. (1995). Developmental expression of fibroblast growth factor receptor-1 (cek-1; flg) during heart development. Dev. Dyn. 202: 115-125.

SWEETMAN, D., SMITH, T. G., FARRELL, E. R., MÜNSTERBERG, A. (2005) Expression of csal1 in pre limb-bud chick embryos. Int. J. Dev. Biol. 49: 427-430.

TOMA, C., PITTENGER, M.F., CAHILL, K.S., BYRNE, B.J., KESSLER, P.D (2002). Human mesenchymal stem cells differentiate to a cardiomyocyte phenotype in the adult murine heart. Circulation 105: 93-98. 
WILLINGHAM, M.C. (1999). Fluorescence labeling of intracellular antigens of attached or suspended tissue-culture cells. In Immunocytochemical Methods and Protocols (Ed. Javois, L.C.), Vol. 115, pp. 121-140, Humana press, New Jersey.

YAN, Z., LIN, Y., JIAO, X., LI, Z., WU, L., JING, W., QIAO, J., LIU, L., TANG, W., ZHENG, X., TIAN, W. (2006). Characterization of ectomesenchymal cells isolated from the first branchial arch during multilineage differentiation. Cells Tissues Organs 183: 123-132.

YATSKIEVYCH, T.A., LADD, A.N., ANTIN, P.B. (1997). Induction of cardiac myogenesis in avian pregastrula epiblast: the role of the hypoblast and activin. Development 124: 2561-2570.

YUAN, S. and SCHOENWOLF, G.C. (1999). Reconstitution of the organizer is both sufficient and required to reestablish a fully patterned body plan in avian embryos. Development 126: 2461-2473.

ZHU, X., SASSE, J., MCALLISTER, D., LOUGH, J. (1996). Evidence that fibroblast growth factors 1 and 4 participate in regulation of cardiogenesis. Dev. Dyn. 207: 429-438.

\section{Further Related Reading, published previously in the Int. J. Dev. Biol.}

See our recent Special Issue Fertilization, in honor of David L. Garbers and edited by Paul M. Wassarman and Victor D. Vacquier at: http://www.ijdb.ehu.es/web/contents.php?vol=52\&issue=5-6

See our Special Issue Developmental Morphodynamics edited by Lev Beloussov and Richard Gordon at:

http://www.ijdb.ehu.es/web/contents.php?vol=50\&issue=2-3

Cellular dynamics and molecular control of the development of organizer-derived cells in quail-chick chimeras Jean-Baptiste Charrier, Martin Catala, Françoise Lapointe, Nicole Le Douarin and Marie-Aimée Teillet Int. J. Dev. Biol. (2005) 49: 181-191

Efficient Cre-mediated deletion in cardiac progenitor cells conferred by a 3'UTR-ires-Cre allele of the homeobox gene Nkx2-5. Edouard G Stanley, Christine Biben, Andrew Elefanty, Louise Barnett, Frank Koentgen, Lorraine Robb and Richard P Harvey Int. J. Dev. Biol. (2002) 46: 431-439

The avian organizer.

T Boettger, $\mathrm{H}$ Knoetgen, L Wittler and M Kessel Int. J. Dev. Biol. (2001) 45: 281-287

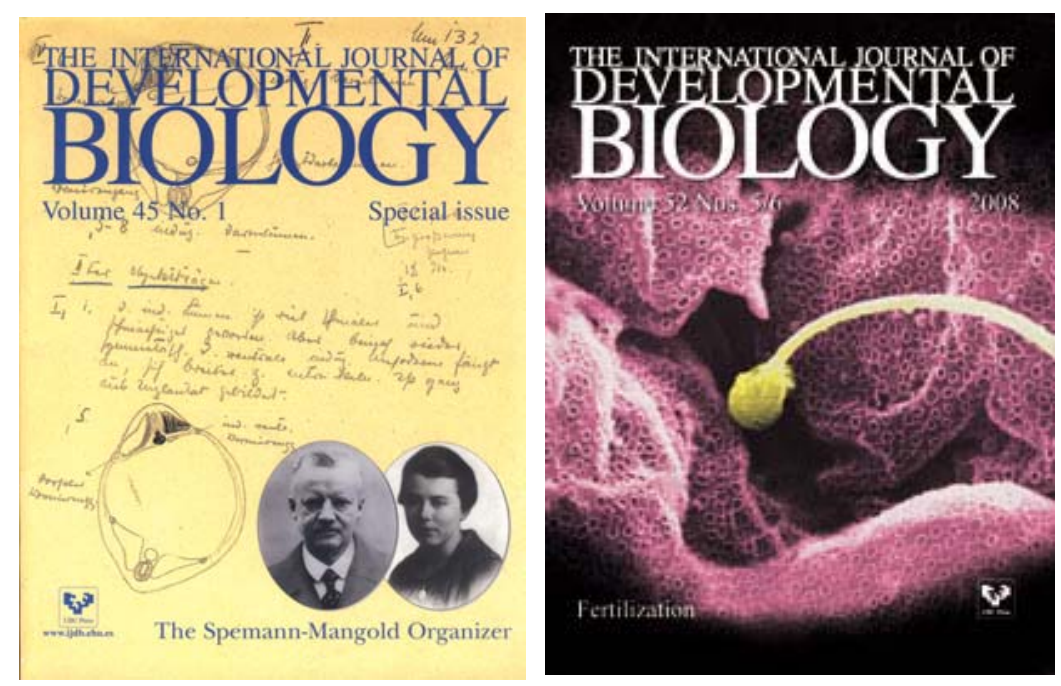

